\title{
O sound design da série Twin Peaks e a herança de Alan Splet
}

\section{The sound design of the Twin Peaks series and Alain Splet's heritage}

Renato Luiz Pucci Junior'1, Fabiano Pereira de Souza² de Comunicações e Artes da Universidade de São Paulo (ECA/USP). Autor de O equilíbrio das estrelas: cinema de Walter Hugo Khouri (2001); Cinema brasileiro pós-moderno: o neon-realismo (2008). Organizador de Televisão: formas audiovisuais de ficção e documentário (2011) e de Televisão: entre a metodologia analítica e o contexto cultural (2016). Bolsista de produtividade do Conselho Nacional de Desenvolvimento Científico e Tecnológico (CNPq), categoria 2. E-mail: renato.pucci@gmail.com. e Fotografia - Criação em Multimeios (2008), graduação em Comunicação Social - Jornalismo (2002) e em Design Digital (1997), todos pela Universidade Anhembi Morumbi. Tem experiência na área de comunicação, com ênfase em jornalismo, em publicações de mídia impressa de larga circulação nacional e online. E-mail: fabian59@gmail.com. 


\section{Resumo}

Este artigo examina o sound design da série televisiva Twin Peaks (TWIN..., 1990-1991), criada por David Lynch e Mark Frost. Analisam-se distorções ou substituições de vozes, técnicas que Lynch havia empregado em um curta e em quatro longas-metragens, com o sound designer Alan Splet. O objetivo é identificar na série, realizada após o término da parceria com Lynch, a persistência do tipo de elaboração sonora de Splet. O exame da mais recente temporada de Twin Peaks (TWIN...,2017) mostra que se intensificaram recursos sonoros das temporadas anteriores, em conjunção com a trama mais ousada em termos narrativos. O artigo fundamentase em Michel Chion quanto ao som e em Luiz Manzano quanto ao sound design. O conceito de brincadeira infinita, de James Carse, e o ensaio de Angela Hague sobre o método investigativo do agente Cooper ajudam a entender a relação entre sonoridade e trama ficcional.

Palavras-chave

Twin Peaks, televisão, ficção seriada, sound design, cinema.

\section{Abstract}

This article examines the sound design of the television series Twin Peaks, created by David Lynch and Mark Frost. The focus is on the distortions or substitutions of voices, which are techniques that Lynch had used in a short and four feature-length films, with the sound designer Alan Splet. The aim is to identify any remains of Splet's type of sound creation in the series, produced after the end of his partnership with Lynch. The analysis of the latest Twin Peaks season (2017) shows sound resources of earlier seasons have been intensified, in conjunction with the more daring plot concerning its storytelling. This article is based on Michel Chion regarding sound and on Luiz Manzano regarding sound design. James Carse's concept of infinite game and Angela Hague's essay on the agent Cooper's investigative method help in understanding the relation between sound and fictional plot.

\section{Keywords}

Twin Peaks, television, serial fiction, sound design, cinema. 
Novas questões surgem a partir da exibição da terceira temporada de Twin Peaks (2017), 25 anos após o término da anterior. A série, originalmente criada por David Lynch e Mark Frost, transformou-se num marco da ficção televisiva, ao passo que a nova temporada, com Lynch à frente, não se limitou a dar continuidade à trama. Aspectos narrativos, técnicos e estilísticos suscitam a ideia de que um novo patamar foi atingido, sem deixar de, ao mesmo tempo, provocar a sensação de uma estranha familiaridade.

No que diz respeito à sonoridade, os novos capítulos trazem à lembrança aquela que é talvez a mais célebre cena de Twin Peaks: "O sonho de Dale Cooper" (interpretado por Kyle MacLachlan) (TWIN..., 1990) ao final do capítulo $1.03^{3}$. O agente do FBI foi à cidadezinha de Twin Peaks para desvendar o assassinato de Laura Palmer (Sheryl Lee), cujo corpo fora descoberto embrulhado em plástico à beira de um lago. Na cena em questão, ele sonha que está num quarto vermelho com Laura e um anão (Michael J. Anderson), que lhe falam de forma estranha (Figura 1). Há bastante tempo sabe-se que os atores enunciaram as frases de trás para frente, para depois a cena ser exibida em reverso, de modo que as palavras soavam quase ininteligíveis (RODLEY, 1997, p. 165-167). Obviamente a elaboração audiovisual de Twin Peaks não se limitava ao brilhantismo da cena. No entanto, pode-se dela partir para a avaliação do empenho de Lynch com a sonoridade de seus filmes e dessa série. 


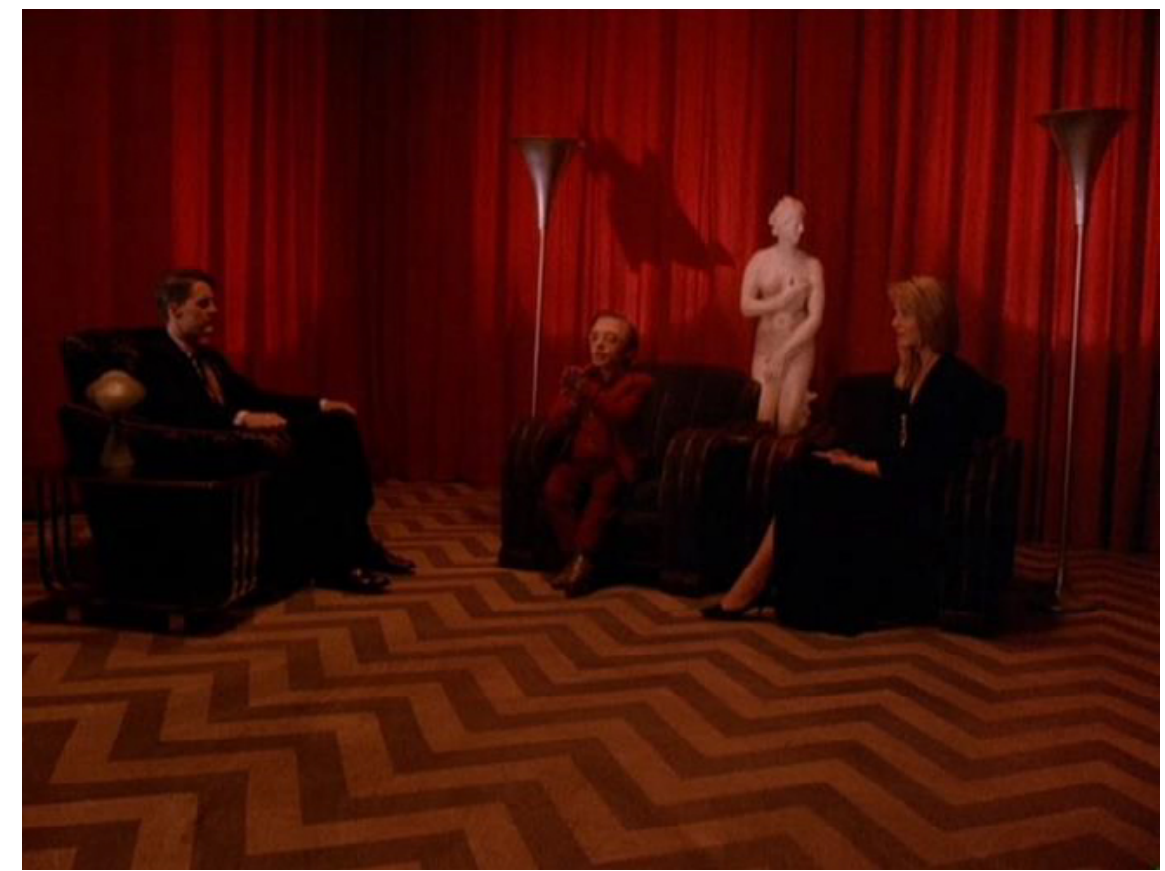

Figura 1: Capítulo 1.03

Fonte: Twin Peaks, 1990.

Um dos pontos a destacar é a participação do sound designer Alan Splet no início da carreira de Lynch. Em Twin Peaks (1990-1991), Splet já não estava na equipe de produção, no entanto há razões para acreditar que seu trabalho em filmes anteriores do diretor deixou uma herança que se materializou na série. Para começar, a ideia para a sonorização da cena no quarto vermelho havia sido pedida por Lynch a Splet, em 1971, para ser usada na cena da fábrica de lápis de Eraserhead (1977) (RODLEY, 1997, p. 165-167). É possível suspeitar que Lynch tenha levado a trabalhos posteriores, inclusive Twin Peaks, sua abertura às experimentações sonoras com Splet. Eis o objetivo central deste artigo: examinar a herança de Splet nos trabalhos do diretor para a televisão. Pretende-se chegar à composição sonora e a seu papel na terceira temporada, no que concerne à criatividade em jogo e à construção de sentidos, capaz de desconcertar mesmo espectadores habituados a séries complexas, no sentido que Jason Mittell (2015) atribui à expressão.

Tendo trabalhado entre os anos 1970 e 1990, numa parceria de 16 anos com Lynch, Splet faleceu em 1994, sendo lembrado principalmente por seu trabalho 
ao lado do cineasta. Ao valorizar efeitos e ambientes sonoros, Lynch abriu para Splet um campo fértil para explorar assincronia e distorções sonoras em diferentes níveis de efeitos, em construções de som em contraponto às imagens.

Sob a direção de Lynch, Splet participou do quarto curta-metragem do diretor, The grandmother (1970), e dos primeiros longas: Eraserhead, O homem elefante (1980), Duna (1984) e Veludo azul (1986). Na filmografia de Splet constam 25 produções como sound designer ou editor de som. Ele trabalhou também em produções como $A$ insustentável leveza do ser (Philip Kaufman, 1988), Sociedade dos poetas mortos (Peter Weir, 1989) e Henry \& June (Philip Kaufman, 1990). Ganhou o Oscar de edição de som de 1980 por O corcel negro (Carroll Ballard, 1979).

Para caracterizar o trabalho que Splet realizou para Lynch, é fundamental retomar algumas informações sobre o som de cinema. David Bordwell avalia que os investimentos, esforços, ajustes, modificações e revisões de tecnologia trazidos com o cinema sonoro a partir de 1927 não representaram uma alternativa radical ao cinema mudo (BORDWELL, 1985, p. 301). O material sonoro foi inserido entre os recursos expressivos já consolidados do cinema clássico hollywoodiano. Nos procedimentos técnicos difundidos de 1927 a 1932, o autor identifica um conjunto altamente coerente de analogias entre imagem e som, entre as construções visuais e auditivas de espaço e tempo narrativos (BORDWELL, 1985, p. 301). A gravação da fala vinculava-se à imagem filmada. Sendo a voz a prioridade e a música um elemento de coesão e capricho narrativo, efeitos sonoros tinham importância menor naquele conjunto.

Sucessivos aprimoramentos nos sistemas sonoros surgiram nas décadas posteriores, com destaque para as melhorias de definição trazidas pelo sistema Dolby, a que Michel Chion (1994, p. 155-156) atribuiu o papel de ter beneficiado todo o campo da sonorização. Chegava então, nos anos 1970, a tecnologia que proporcionava uma grande mudança na forma de se lidar com o som fílmico, tanto na produção quanto na audição das plateias (MANZANO, 2013, p. 15). Com a evolução proporcionada pelo sistema multicanal Dolby, nascia também 
a função de sound designer, contemporânea portanto de um de seus principais aliados técnicos.

Sound design é uma função criada para estabelecer a identidade sonora do filme desde o início do projeto, aplicando ao som tipos de construção - por meio de edição, efeitos e mixagem - correspondentes à estética visual prevista pelo diretor. Dessa forma, cabe ao responsável proporcionar a comunicação clara entre o cineasta e os chefes das equipes de som direto, edição de som e mixagem, o que antes não era regra. O sound designer precisa compreender a complexidade de criar a identidade sonora do filme:

\footnotetext{
Para que isso se concretize, é necessário que o pensamento sonoro comece o mais cedo possível dentro da realização e que se tenha um profissional conhecedor de todo o percurso do som dentro de um filme, ciente dos problemas e características de captação e edição, extensivos às possibilidades estéticas e às questões técnicas da edição e da mixagem. Esta idealização poderia remeter no mínimo ao início do trabalho de montagem de imagem, quando a narrativa começa a efetivamente se estruturar. Chega-se assim a um projeto de som para o filme, criando um desenho sonoro que se concretizará na mixagem. (MANZANO, 2013, p. 16)
}

Manzano explica que a aposta numa maior sofisticação no trabalho com a banda sonora ocorria por meio de uma articulação extrema entre imagem e som (2013, p. 16). Preferencialmente, o elemento sonoro era pensado desde o roteiro, como é o caso da parceria entre Lynch e Splet. Ainda segundo Manzano: "Seria o equivalente a pensar em como a câmera pode contar uma história: através do controle dos elementos que compõem a trilha, pode-se ter uma história diferente ou até levar-se a banda sonora a um papel determinante na condução da narrativa" (2013, p. 16).

A melhor qualidade técnica na reprodução sonora propiciou mais sofisticação no emprego de efeitos. Mas a valorização do som no cinema dos anos 1970 não se restringia à tecnologia. Em Hollywood despontava a primeira geração de cineastas oriundos das faculdades de cinema dos Estados Unidos. A cultura fílmica daqueles novatos também fazia com que eles acreditassem em novas formas de trabalhar o som. Francis Ford Coppola e George Lucas se associaram a dois dos primeiros 
e mais renomados sound designers, respectivamente, Walter Murch e Ben Burtt. Diferentemente desses dois, Alan Splet não trazia formação nem treinamento acadêmicos. Antes de trabalhar com áudio, era contador. Lynch tampouco tinha formação em cinema, mas em artes plásticas.

Autor de um livro sobre a filmografia de Lynch, Chion destaca a importância histórica do cineasta pela valorização de efeitos sonoros em ambientes e paisagens sonoros. Diz o autor que Lynch renovou o cinema por meio do som. Ele aponta que o continuum sonoro do sound design é paradoxalmente repleto de descontinuidade, pois o diretor teria assimilado que, para unir (construir), é preciso primeiro separar. Lynch faria isso, sobretudo e de maneira mais original, com o som - exatamente o recurso que, devido à sua natureza temporal, é mais associado do que a imagem a um continuum (CHION, 2003, p. 70-71).

Por sua vez, Mauro Pommer afirma que em Lynch o uso da imagem é em grande parte conduzido pelo som: "cabe ao som proporcionar o ritmo narrativo e operar como sustentáculo à duração inabitual de certos planos, que se tornariam artisticamente inviáveis se não fossem conduzidos pela trilha sonora" (2000, p. 301). Para ele, o cineasta cria o aspecto visual surrealista, somando a tais planos sons que podem amplificar esse distanciamento da realidade cotidiana. Lynch não priorizaria a decupagem, nem os movimentos de câmera para destacar situações que conotassem inércia (POMMER, 2000, p. 301).

Ao contrário desses autores, que escreveram sobre a sonoridade dos filmes de Lynch sem citar Splet ou apenas mencionando-o de passagem, Eduardo Santos Mendes refere-se ao sound designer quando indica que a capacidade do cinema ser sensorial causa sensações claras, físicas. É nesse aspecto que considera Splet um aperfeiçoamento de Murch, de O poderoso chefão (1972) e Apocalipse now (1979), filmes de Coppola. Segundo Mendes, Murch se prende à verossimilhança: "Ele volta. Quando ele delira, ele faz uns delírios lindos e maravilhosos, no final ele justifica. Ele tem que justificar de alguma forma, ele tem que deixar aquilo verossimilhante de alguma forma. E o Splet não" (MENDES, 2016, p. 289). Assim, o autor indica o que considera a principal contribuição de Splet: 


\begin{abstract}
A forma como ele trabalha com ambiente, que ele faz do ambiente um pulso vivo, um personagem. Você pode usar o ambiente para dar tridimensionalidade à imagem, é a função básica dele. Mas ele usa ambiente para contar história. A função do ambiente dele é narrativa, não para gerar verossimilhança. [...]. Eu gosto da forma com que ele faz que objetos ou mesmo seres inanimados ou mesmo animados criem personalidade. Passam a ser personagens, seres vivos, com raiva, com ódio, com violência. [...]. E, acima de tudo, a liberdade com que ele trata sons, pensando muito mais no caráter sonoro daquilo, do que ele consegue tirar como pulso, como timbre, como sonoridade propriamente dita, do que da sua verossimilhança. Então, essa liberdade de pegar um som de um outro universo e trazer para um universo onde você nunca o juntaria. (MENDES, 2016, p. 292)
\end{abstract}

Mendes (2016, p. 293) nota que com Splet o som não é externo, não é da imagem, mas sim um elemento interno, uma personagem. "Um vento dentro de um quarto com a janela fechada, mas tudo bem, você aceita". O autor complementa: "A voz deixa de ter uma característica semântica e você trabalha só com a questão de timbre, de emissão, como qualquer outro efeito sonoro, só que é humano" (MENDES, 2016, p. 294).

A partir dos traços gerais expostos pelos autores citados, a composição sonora de Twin Peaks será examinada em detalhe.

\title{
Mistérios de Lynch na TV
}

Ao surgir o cinema sonoro, com O cantor de jazz (Alan Crosland, 1927), a fala era instrumento primordial da narrativa bem como a voz dos astros e estrelas. A música cumpria a função de direcionamento e intensificação emocional. Os efeitos sonoros eram, quase sempre, meros acessórios de verossimilhança. Com sincronia entre sons e imagens diegéticos, essa tornou-se a estética sonora clássica do cinema ${ }^{4}$.

A televisão trouxe particularidades em relação ao som. Num texto de 1981, Muniz Sodré defendeu que os diálogos televisivos atribuíam tamanha 
importância ao elemento verbal que ele terminava impondo-se às imagens. 0 autor detectava uma proximidade maior entre a TV e o rádio do que entre aquela e o cinema. "É que o compromisso com o real histórico (em termos institucionais, com a informação jornalística) impele a tevê a uma lógica de demonstração, de explicação, que percorre todas suas possibilidades expressivas" (SODRÉ, 1981, p. 74). Como a TV atende a diversas formas de comunicação e entretenimento, como jornais, programas de auditório, esportes, entre outras, a ficção era influenciada pelo didatismo informativo dessas atrações e também se pautava por esclarecer oralmente o que era mostrado na imagem.

À parte o fato de que desde os anos 1990 o diagnóstico de Muniz Sodré deva ser relativizado em razão do crescente cuidado com as imagens em parte da produção televisiva, de fato a clareza dos diálogos exigia um tratamento sonoro, que ainda permanece na produção televisiva. Eis a prescrição de Herbert Zettl:

Os cinco principais fatores estéticos no controle de som são: ambiente aguçar um evento por meio de sons ambiente; figura/fundo - enfatizar a fonte de som mais importante em relação aos sons gerais de fundo; perspectiva - fazer a correspondência de imagens em close-up com sons próximos e planos gerais com sons distantes; continuidade - manter a qualidade de som ao combinar várias tomadas; e energia - adequar a força e a intensidade das imagens com uma intensidade de som parecida. (ZETTL, 2011, p. 161)

Sons ambientes são os mais notáveis entre os efeitos sonoros na filmografia de Lynch e no seu trabalho para a TV. Para entender a estruturação sonora de Twin Peaks, examine-se primeiro sua trama. A série se caracteriza por uma combinação de gêneros, dentre os quais o investigativo, pois a história é desencadeada pela descoberta do corpo de Laura Palmer, estudante de ensino médio admirada na cidade, mas que guardava perigosos segredos.

O padrão em narrativas seriadas de investigação da literatura, do cinema e da televisão apresenta personagens cerebrais clássicos, como Dupin, de Edgar Allan Poe, e Sherlock Holmes, de Conan Doyle, cujos raciocínios e métodos costumam ser apresentados com clareza didática. A partir desse entendimento 
preliminar, pode-se explorar o processo investigativo do agente Cooper e os efeitos narrativos e expressivos da obra.

Angela Hague publicou um detalhado ensaio sobre o peculiar método investigativo de Cooper (1995, p. 130-143). Para a autora, a tradicional desconfiança da dimensão intuitiva da mente dos detetives é par habitual da insistência de que as histórias tenham fim definido, para que a racionalidade e a ordem sejam restabelecidas. Hague usa a definição de Dorothy L. Sayers para afirmar que as histórias de detetive apresentam uma perfeição aristotélica de começo, meio e fim, cujo horror passa assim que elas são contadas (HAGUE, 1995, p. 131). Essa estrutura é derrubada pela linha de narrativa detetivesca de que Twin Peaks faz parte. Ela não só viola as expectativas aristotélicas ao recusar uma conclusão clara e ordenada por silogismo, deixando uma sensação de incompletude e inquietação, como também rejeita a possibilidade de oferecer o prazer da purificação emocional que Aristóteles chamou de catarse (1979, p. 245). Em vez disso, produz pena, medo e horror. William Spanos denomina "terrível incerteza" esse procedimento de narrativas antidetetivescas, que abrem "novos reinos da consciência sem entraves pelas restrições do telos e positivismo" (HAGUE, 1995, p. 131-133).

Twin Peaks associa-se ao que James Carse chama de brincadeira infinita (1986, p. 3). Segundo o autor, um jogo finito se caracteriza por regras imutáveis, fronteiras espaciais e temporais e conclusões em que alguém vence, a exemplo das tradicionais narrativas de detetive. Quando essas fronteiras são dissolvidas, temos os jogos infinitos, estratégia de que a série lança mão. Carse (1986, p. 35) divide os participantes em jogadores finitos (treinados) e infinitos (educados). Os primeiros são preparados contra as surpresas, ao passo que os segundos são preparados para a surpresa. Em Twin Peaks esses papéis podem ser reconhecidos respectivamente na conduta racional do xerife Truman (Michael Ontkean) e na postura intuitiva de Cooper. Um típico exemplo do método do agente está no capítulo 1.03, quando Cooper faz alguém dizer, um a um, o nome dos suspeitos e seu vínculo com Laura. A cada nome, Cooper atira uma pedra numa garrafa de vidro colocada num toco de árvore, até que uma das pedras quebra a garrafa, 
indicando um suspeito com mais potencial de culpa. Sonhos também guiam o detetive em outras passagens.

Porque a "técnica dedutiva" intuitiva de Cooper estrutura o processo inteiro de investigação na série, é necessário examinar como sonhos, visões e intuição funcionam como processos psicológicos. E o psiquiatra de plantão em Twin Peaks não é Dr. Jacoby, mas C. G. Jung, que mais decididamente explorou o papel da consciência intuitiva na mente inconsciente ${ }^{5}$. (HAGUE, 1995 , p. 136, tradução nossa)

Provém de Jung a ideia da inconsciência como uma perda do ego que elimina as fronteiras que separam o "Eu" do resto do mundo, enquanto dissolve a distinção entre sujeito e objeto. Somos parte um sistema coletivo e complacente nessa instância da mente, quando desistimos do poder e do controle que caracterizam a atividade consciente, uma área em que o pensamento opositivo binário, lógico e categórico desaparece (JUNG, 1969, p. 22-23). Nessa condição, é mais simples atentar às intuições, sonhos e coincidências estranhas porque a psique inconsciente consegue despedaçar as barreiras do espaço-tempo e conexões causais aparentes que existem em nossa compreensão consciente. Hague diz que a intuição sem causa e não linear opera de acordo com um princípio conectivo "sincrônico" que relativiza ou nega os conceitos de tempo e espaço, focando em vez disso em "coincidências significativas" (HAGUE, 1995, p. 136-137). Essa observação ajudará a entender aspectos sonoros a serem destacados mais adiante.

Quando Cooper revela sua técnica intuitiva a Truman, no capítulo 1.04, ele diz "decifre o código, desvende o crime". O "código" é o sonho do agente com o quarto vermelho. Cooper abre mão do raciocínio causal em favor do que Jung chama "sincronia" (outro termo essencial nas relações entre áudio e vídeo), um "princípio conector sem causas", que "permite a significância emergir de agrupamentos ou to examine how dreams, visions, and intuition function as psychological processes. And the psychiatrist on call in Twin Peaks is not Dr. Jacoby but C. G. Jung, who has most thoroughly explored the role of intuitive consciousness in the unconscious mind". 
aglomerações simultâneos de fenômenos; coincidências significativas substituem a lógica linear"6 (HAGUE 1995, p. 138, tradução nossa).

Rogério Ferraraz (2003, p. 94) evidencia a recorrência de duplos nos filmes do diretor: "seja real, imaginado ou desdobrado em vários personagens que se completam e, por isso, se enfrentam, já que representam as faces opostas de uma personalidade". Ele reconhece que, em Twin Peaks, o duplo é um ponto essencial, e cita figuras duplicadas: Leland Palmer (Ray Wise) e Bob (Frank Silva), Laura Palmer e sua prima Maddy Ferguson (Sheryl Lee) e Cooper e seu doppelgänger (FERRARAZ, 2003, p. 96). Segundo o autor, no universo de Lynch não é a explicação do que é visto ou ouvido em cena o que mais conta, mas sim as atmosferas e efeitos de estranhamento que ele cria - no sentido do que Carse chama de jogo infinito. "Suas imagens labirínticas e seus sons perturbadores causam o pânico da não-compreensão" (FERRARAZ, 2003, p. 106).

\begin{abstract}
O som, nos filmes de Lynch, também é usado como um elemento fundamental para evidenciar as fissuras da identidade, refletindo-se no descolamento (e no deslocamento) entre o que vemos e o que ouvimos. [...]. Não pela cenografia ou direção de arte [...], mas pelo tratamento dado aos personagens através do som: ruídos, música e silêncio. Esse modo de tratar o som passa pelo fascínio que Lynch tem pelos contrastes e pelas contradições. Ele transporta esse fascínio para seus filmes, trabalhando sempre com contrastes e contrapontos sonoros. (FERRARAZ, 2003, p. 160-161)
\end{abstract}

Cabe analisar o quanto disso chegou como herança estética de som a Twin Peaks, já sem a parceria com Splet.

\title{
Sound design em Twin Peaks dos anos 1990
}

Alice Kuzniar (1995, p. 121) observa que na série há um fetiche vocal, uma espécie de fixação recorrente no uso da voz como elemento sonoro para 
experimentações expressivas, como as falas das personagens nas cenas do quarto vermelho. A autora também aponta substituições, quando o que é ouvido está isolado do que é visto, de modo a instigar o desejo da completude (KUZNIAR, 1995, p. 121). Esses recursos já eram utilizados nos filmes de Lynch com Splet, como em humanos que latem e piam em The grandmother, o "tubérculo" que chora como um bebê em Eraserhead, a mulher que grita enquanto são ouvidos rugidos em $O$ homem elefante. O procedimento é mais claramente evidenciado em stills que acompanham fragmentos de diálogo sem relação clara com a trama, frequentemente apresentando vozes ainda não ouvidas. A voz isolada, nos lembrando de nossa limitada perspectiva, atiça o desejo por suplementação visual (KUZNIAR, 1995, p. 121). Outra característica marcante é a música como um efeito sonoro de fundo, numa única nota executada de forma prolongada, acentuando o clima de mistério, como já acontecia em The grandmother e em Eraserhead.

Há em Twin Peaks exemplos de contraponto entre som e imagem, além de distorções sonoras que resgatam aspectos do que havia sido visto e ouvido nos filmes de Lynch. O trabalho de distorção vocal, a exemplo do realizado em Duna, pode ser reconhecido na última cena do "Piloto", quando Sarah Palmer (Grace Zabriskie) grita ao ter a visão do colar de sua filha Laura sendo retirado do esconderijo sob a pedra. Em 1.03, Cooper tem o sonho com o quarto vermelho, conforme descrito no início do artigo. Em 1.04, no enterro de Laura, numa briga entre Bobby (Dana Ashbrook) e James (James Marshall), a voz do primeiro é distorcida de forma bestial.

No capítulo 2.01, quando o som da risada de Bob é distorcido, acentuando o caráter amedrontador do personagem, foram retomadas as composições de som sem caráter naturalista (entendendo naturalismo como a procura do "parecer real", típica da narração audiovisual clássica). Em 2.04, um super close-up de um orifício na parede traz sons estranhos que lembram rajadas de ar e notas musicais com efeito análogo ao de trovões, e uma espécie de bipper eletrônico, como o do aparelho hospitalar de controle de batimentos cardíacos, em intervalos cada vez 
mais curtos, além de sons distorcidos da voz de uma menina dizendo "daddy" repetidas vezes. Na imagem, efetua-se travelling para trás, com a câmera girando sobre si mesma, o que antecede a imagem de Leland Palmer, pai de Laura, enquanto o som do bipper torna-se constante, como a indicar a morte de alguém. Em 2.07, durante o assassinato de Maddie Ferguson, a voz de Bob é novamente distorcida, acompanhando a câmera lenta num efeito de rugido.

Em 2.09, Bob novamente emite sonoridades estranhas quando, durante sua possessão de Leland Palmer e prestes a dançar com Donna Hayward (Lara Flynn Boyle), dá um grito simultâneo ao estrondo de um trovão. Antes de o Major Briggs (Don S. Davis) ser interrogado, no início do capítulo 2.13, uma espécie de sonho do personagem traz distorções vocais em off e depois a voz de Cooper com um eco distorcido, até que a cena é cortada para o interrogatório na delegacia da cidade. Uma gota cai do sprinkler do teto com som amplificado. Quando Josie Packard (Joan Chen) abre a porta para Eckhardt (David Warner), no capítulo 2.15, um efeito que fica no limiar entre o sonoro e o musical dá a impressão de um trovão para ressaltar a surpresa aflitiva da moça. Depois de bater em James com sua pistola e tentar controlar Evelyn (Annette McCarthy), Malcolm (Nicholas Love) conversa com ela em velocidade sonora natural, ao passo que a imagem segue em câmera lenta. Quando Evelyn o mata, seu gritos são distorcidos a ponto de parecerem latidos ou rugidos distantes.

A risada de Bob logo após a morte de Josie no capítulo 2.16 é distorcida, definindo ainda mais o caráter sobrenatural da cena, e é com distorção sonora também que ouvimos gemidos da moça enquanto vemos sua imagem na maçaneta da cômoda. Em 2.18, quando uma coruja voa junto a Cooper, Truman e Andy (Harry Goaz) na caverna, os efeitos sonoros que produz são distorcidos e amplificados. Em 2.20, após pratos se espatifarem no chão da lanchonete, ao lado de Cooper, o gotejamento em câmera lenta em algum deles tem o som artificialmente amplificado. A mensagem com voz distorcida eletronicamente de Sarah para o Major Briggs, no capítulo 2.22, lembra os efeitos de Duna. A ida de Cooper ao quarto vermelho para salvar Annie traz de volta mais do efeito da voz reversa tão característico da série. 
O principal exemplo de criatividade sonora das duas primeiras temporadas, como dito no início do artigo, são as vozes gravadas de maneira invertida. Algumas distorções e amplificações têm certa recorrência em produções com uso mais tradicional de efeitos sonoros. De qualquer modo, em conjunto, essas soluções reiteram a estranheza e as dúvidas deixadas pela investigação ao longo da série, acrescentando um efeito sombrio sobre o caráter das personagens e estimulando o espectador a duvidar de possíveis aspectos lógicos do trabalho de Cooper e da própria narrativa.

\section{Twin Peaks no século XXI}

O ator Kyle MacLachlan, envelhecido, divide-se na terceira temporada entre Cooper e seu duplo. A ação de cada um situa-se em localidades diversas, como Nova York e Las Vegas, enquanto personagens, interpretados pelos mesmos atores das temporadas originais, seguem com suas vidas em meio a uma nova geração, representada por seus filhos. A voz continua capitaneando os elementos mais criativos do sound design, agora assinado pelo próprio Lynch. Alguns capítulos retomam o quarto vermelho, mas há novos exemplos de experimentação de som a partir da voz.

No capítulo 3.03, a primeira imagem é trêmula e mostra Cooper de braços abertos com fundo escuro e sons de fluxo intenso de ar ou rumor de máquinas distantes. Estabelece-se um clima onírico. Surge Naido (Nae Yuuki), mulher aparentemente oriental (sobre seus olhos há só pele inchada com cicatrizes, seu gestual é o de uma pessoa cega), em imagens entrecortadas como animação stop motion. Ela fala para Cooper sem que ouçamos o som da cena, apenas um suave rumor de fundo. Com distância e ressonância realistas em relação ao que se ouviria na posição da câmera em plano aberto num ambiente amplo, algo raro na produção audiovisual de massa, Cooper pergunta onde estão. Ela fala, mas o som é mais fragmentado do que as imagens.

Batidas numa superfície metálica vêm de fora do campo de visão. A mulher faz gestos pedindo silêncio e que ele aguarde. Cooper vê uma espécie de aparelho 
embutido na parede. Tenta ir em direção a ele, a mulher o impede, aflita, com cacos vocais e movimentos de braço que soam como golpes cortantes de vento e de lâmina. Ela o leva para o lado de fora. Estão no espaço sideral, estrelas acima e abaixo, o que de forma surrealista destrói a noção de espaço contínuo. Pisam numa caixa metálica com uma espécie de caldeira antiga e rudimentar (Figura 2). Ela puxa uma alavanca, é eletrocutada e despenca no espaço. Uma nuvem forma um rosto que sussurra "Blue Rose".

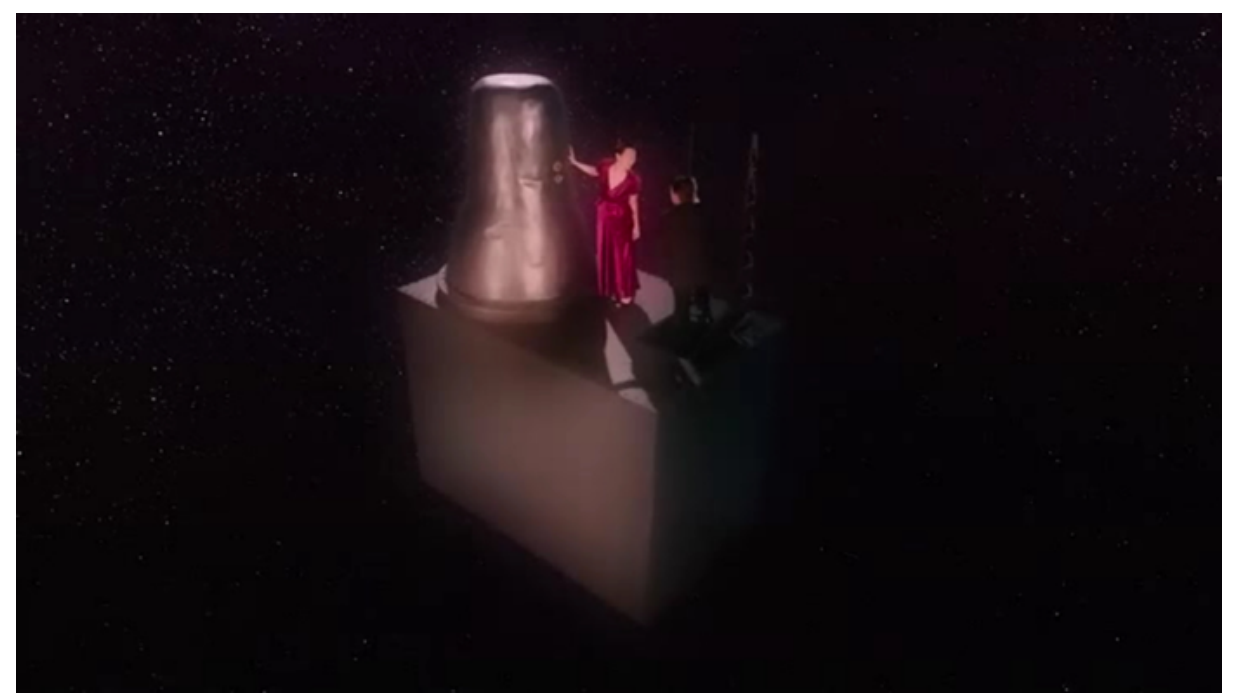

Figura 2: Capítulo 3.03

Fonte: Twin Peaks, 2017.

Cooper volta à sala onde estava. Outra mulher diz: "quando estiver lá, você já estará lá [...]. Melhor se apressar, minha mãe está chegando", com a distorção sonora equivalente à do quarto vermelho. Cooper é tragado para dentro do aparelho embutido, ao som de suave pipocar de corrente elétrica. Numa transferência surreal, Cooper assume a identidade de um homem de Las Vegas, casado e com um filho. Limitações físicas e mentais o deixam apalermado. Em 3.06, um semáforo no vermelho traz outro zunido elétrico sem que nada indique irregularidade de funcionamento.

Em 3.08, há uma atmosfera de tensão e medo associada ao uso da música instrumental Threnody for the Victims of Hiroshima, de Krzysztof Penderecki. A trama é interrompida pela imagem noturna de um deserto com a legenda 
"16 de julho de 1945, White Sands, Novo México", data e local históricos da primeira explosão atômica, que no capítulo marca a entrada da música. Passada a explosão, pessoas vagam num remoto posto de gasolina sob luz entrecortada. O som é também fragmentado, sugerindo efeito da radiação. Em imagens em preto e branco, uma mulher está numa sala de estar enquanto a música distante é ouvida por meio de um gramofone próximo a ela. Um som de respiro mecânico sincopado lembra o de uma máquina de respiração artificial, porém origina-se da caldeira rudimentar vista em 3.03 e coincide em ritmo com a luz que emana dela.

Adiante, outra imagem noturna do deserto traz a legenda "1956". Um casal num carro é abordado pelo que parecem ser zumbis, que falam com voz distorcida, um som que parece estática. Estabelece-se a típica tensão de filme de terror. Um desses seres de voz distorcida ataca uma estação de rádio, mata a recepcionista e depois o DJ, espremendo seus crânios. Ao assumir o microfone da rádio repete com voz metálica: "Esta é a água, e este é o poço. Beba tudo e desça. O cavalo é o branco dos olhos e o escuro por dentro". Pessoas que ouvem a transmissão da rádio em outros lugares despencam no chão, não se sabe se desmaiadas ou mortas.

Em 3.09, Lynch optou pela estranheza cômica, quando Jerry Horne (David Patrick Kelly) está numa área florestal e ouve seu pé Ihe dizer "não sou seu pé" com uma voz aguda distorcida. Em 3.14, na floresta de Twin Peaks retorna a mulher oriental, que balbucia em voz distante, cortada, desconexa. Abduzido através de um turbilhão de luz que se forma no ar para o que parece ser uma dimensão paralela, Andy se encontra com o gigante numa sala em que uma tela circular no teto exibe cenas, inclusive do zumbi, com som tão trepidante quanto as imagens (Figura 3). 


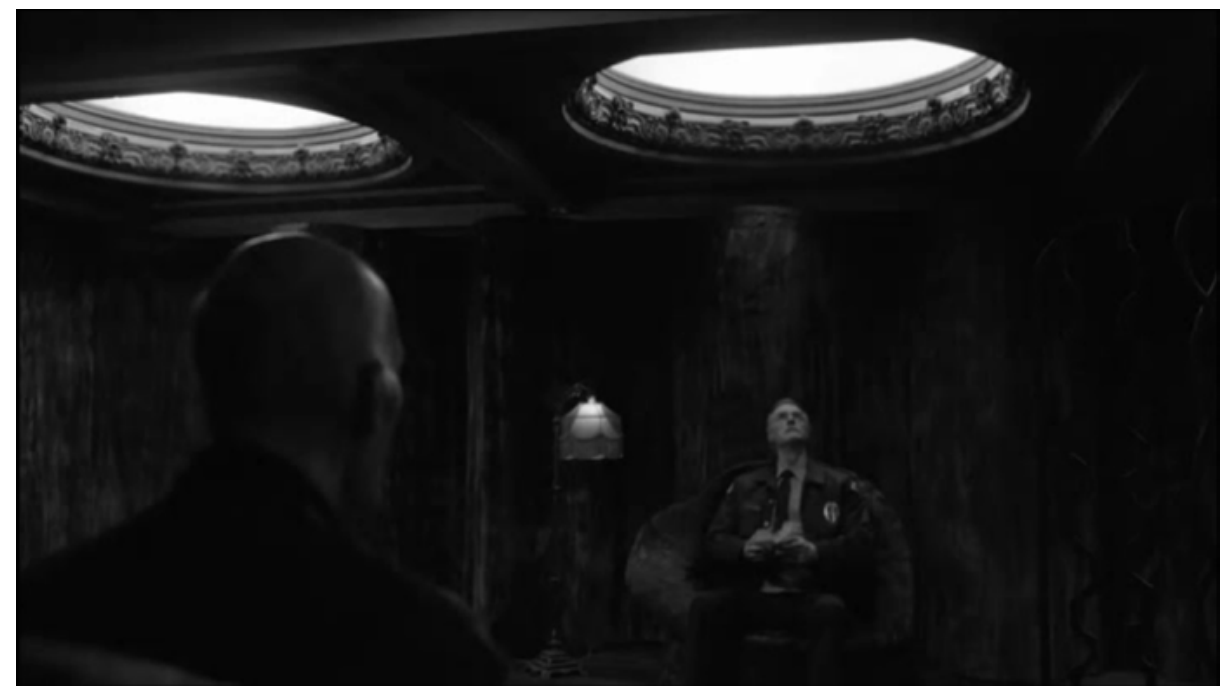

Figura 3: Capítulo 3.14

Fonte: Twin Peaks, 2017.

Em 3.15, no local em que a versão maléfica de Cooper procura Phillip Jeffreys, as vozes das pessoas têm o mesmo efeito do quarto vermelho. Uma voz metálica, supõe-se que de Jeffreys (David Bowie), que aparece numa imagem em preto e branco, parte de um objeto grande e escuro, semelhante à caldeira do capítulo 3.03, com uma fumaça a sair por um tubo em direção a um globo transparente. Em 3.16, em sobreposição de imagens diretamente do quarto vermelho para o hospital em que Cooper se recupera, aparece Phillip Gerard (Al Strobel) falando no estilo do quarto vermelho.

A terceira temporada de Twin Peaks, além da marcante inserção de repertório musical pop, expande o uso de efeitos sonoros associados à voz e o tratamento das vozes como se fossem efeitos sonoros. Essa característica ecoa práticas do movimento surrealista, no qual, conforme explica Eduardo Peñuela Cañizal, a realidade superior se alcança por "associações de coisas aparentemente desconexas ou, então, pelos chamados processos oníricos, ou seja, da decifração dos significados enigmáticos que se elaboram nos sonhos" (CAÑIZAL, 2006, p. 143). O autor aponta a linguagem como a principal subversão do movimento, em que os moldes formulados pela consciência eram intoleravelmente restritivos à liberdade (CAÑIZAL, 2006, p. 145). Nesse texto, anterior à terceira temporada 
de Twin Peaks, Cañizal reconhece em Lynch um seguidor ilustre do surrealismo. Após a exibição dos novos capítulos, pode-se entender o quanto Lynch radicalizou a proposta dos anos 1990 .

\section{Comentários finais}

Nas duas primeiras temporadas de Twin Peaks, é possível reconhecer procedimentos sonoros típicos do sound design de Alan Splet nos filmes de Lynch. O contraponto sonoro proporciona combinações de sons sem relação verossímil com a imagem, para gerar estranhamento, em consonância com o enredo e a atmosfera da série. Essa construção funciona de forma alinhada com a proposta de jogo infinito da investigação de Twin Peaks, em que mistérios adicionais surgem para gerar novas hipóteses, tanto de Cooper e outros personagens, quanto do espectador. Personagens e situações se deslocam em efeitos de duplo, de modo a sempre adiar a resolução dos mistérios, e quando um destes é elucidado, caso da morte de Laura, novos mistérios envolvem as personagens, aos quais o som contribui esteticamente. Como escreveu Fabrício Felice (2018, p. 605-606), em Twin Peaks, imagens e sons nítidos e efêmeros de caráter onírico impelem o espectador "mais a uma apreciação estética das sensações provocadas por sua materialidade audiovisual do que a um acompanhamento investigativo das razões e motivações dos personagens da trama".

O método intuitivo de Cooper representou uma ruptura em relação às incontáveis séries televisivas de investigação. O sound design contribuiu nesse sentido, mantendo-se coeso com as marcas autorais de Lynch desenvolvidas em sua parceria com Splet. Algumas das soluções sonoras acima identificadas resgatam procedimentos típicos da filmografia do gênero do horror, como gotas com som amplificado e efeitos de trovão para incutir sensação de temor. Por outro lado, a inovação no sound design se dá porque a distorção vocal revela bestialidade em meio a expressões assustadoras de personagens em situações de agressividade. Em O homem elefante, Veludo azul e Duna (e bem mais em The grandmother), as distorções vocais dispensavam qualquer alteração na fisionomia ou no gestual 
das personagens, no máximo associadas à câmera lenta, resultando num efeito sonoro mais imprevisível.

O princípio conectivo sincrônico, na acepção de Jung, relativiza ou nega os conceitos de tempo e espaço. Por sua vez, coincidências significativas, conforme explicado por Hague, norteiam boa parte dos exemplos de contraponto sonoro, de modo a manter e gerar novos estranhamentos, privilegiando a dúvida de matriz intuitiva em detrimento das certezas e elucidações lógicas tanto na investigação fictícia, como na compreensão do espectador.

Considerando-se o raro uso de contrapontos sonoros na filmografia de Splet sem Lynch, é plausível supor que as construções contrapontísticas já eram desde os primeiros longas-metragens uma demanda do cineasta. Splet contribuía de forma singular com sua audição acurada (pela sua formação musical e limitação devido à acentuada miopia) e uma rara sensibilidade para fazer o som render em efeitos de caráter emocional. Mais do que isso, a marca do sound designer era o aspecto sensorial potencializado pela adição de camadas de efeitos sonoros a sons não falados nem musicais.

Nas primeiras temporadas de Twin Peaks, com o cineasta atribuindo a terceiros a direção de vários capítulos, numa mídia de alcance muito maior que o circuito de exibição de seus filmes, essas construções de efeitos sonoros são mais espaçadas e o clima soturno de tristeza e estranhamento depende muito da trilha musical, mérito em grande parte do compositor Angelo Badalamenti. Os efeitos sonoros, tão valorizados na parceria de Lynch e Splet, voltaram mais diversificados na temporada de 2017, tendo a voz como principal matériaprima em composições que surpreendem pela estranheza, por vezes criando contrapontos em relação às imagens. Como sound designer, Lynch honra assim as inovações que introduziu décadas antes com Splet. 


\section{Referências}

ARISTÓTELES. Poética. São Paulo: Abril Cultural, 1979. (Coleção Os Pensadores: Aristóteles, v. 2).

BORDWELL, D. The introduction of sound. In: BORDWELL, D.; STAIGER, J.; THOMPSON, K. The classical Hollywood cinema. Nova Iorque: Columbia University Press, 1985.

CAÑIZAL, E. P. Surrealismo. In: MASCARELLO, F. (org.). História do cinema mundial. Campinas: Papirus, 2006. p. 143-155.

CARSE, J. P. Finite and infinite games: a vision of life as play and possibility. Nova Iorque: The Free Press, 1986.

CHION, M. Audio-vision. Nova Iorque: Columbia University Press, 1994.

CHION, M. David Lynch. Barcelona: Paidós, 2003.

FELICE, F. O sonho americano de David Lynch. Imagofagia, Buenos Aires, n. 17, p. 602-610, abr. 2018.

FERRARAZ, R. O cinema limítrofe de David Lynch. 2003. Tese (Doutorado em Comunicação e Semiótica) - Pontifícia Universidade Católica de São Paulo, São Paulo, 2003.

HAGUE, A. Infinite games: the derationalization of detection in Twin Peaks. In: LAVERY, D. Full of secrets: critical approaches to Twin Peaks. Detroit: Wayne State University Press, 1995. p. 130-143. 
JUNG, C. G. The archetypes and collective unconscious. Princeton: Princeton University Press, 1969.

KUZNIAR, A. Double talk in Twin Peaks. In: LAVERY, D. Full of secrets: critical approaches to Twin Peaks. Detroit: Wayne State University Press, 1995. p. $120-129$.

MANZANO, L. A. Do editor de som ao sound designer, os ecos de uma evolução. Filme Cultura, Rio de Janeiro, n. 58, p. 15-19, jan.-mar. 2013.

MENDES, E. S. Entrevista 2016 C. [Entrevista cedida a] Fabiano Pereira de Souza. In: SOUZA, F. P. Alan Splet: o sound design de Veludo azul e a polifonia de efeitos sonoros. Dissertação (Mestrado em Comunicação). Universidade Anhembi Morumbi, São Paulo, 2016. p. 272-310. Disponível em: https://bit.ly/2UoJHIt. Acesso em: 28 jul. 2018.

MITTELL, J. Complex TV: the poetics of contemporary television storytelling. Nova Iorque: New York University Press, 2015.

POMMER, M. E. O tempo e o som: o inconsciente segundo Lynch e Hitchcock. In: SOCINE (org.). Estudos de cinema Socine II e III. São Paulo: Annablume, 2000. p. 296-305.

REIS, C.; LOPES, A. C. Dicionário de teoria da narrativa. São Paulo: Ática, 1988.

RODLEY, C. Lynch on Lynch. Londres: Faber and Faber, 1997.

SODRÉ, M. O monopólio da fala: função e linguagem da televisão no Brasil. Petrópolis: Vozes, 1981. 
TWIN Peaks (Temporadas 1 e 2). Direção: David Lynch et al. [S. I.]: Lynch/Frost Productions, 1990-1991. 10 DVDs (1501 min.), son., color.

TWIN Peaks. Direção: Mark Frost e David Lynch. Nova Iorque: Showtime, 2017. 18 vídeos (1025 min.), son., color.

ZETTL, H. Manual de produção de televisão. São Paulo: Cencage Learning, 2011. submetido em: 05 ago. 2018 | aprovado em: 05 nov. 2018 